\title{
Receptor interacting protein 3-induced RGC-5 cell necroptosis following oxygen glucose deprivation
}

\author{
Wei Ding ${ }^{1 \dagger}$, Lei Shang ${ }^{1 \dagger}$, Ju-Fang Huang ${ }^{1}$, Na Li ${ }^{1}$, Dan Chen ${ }^{1}$, Li-Xiang Xue ${ }^{2^{*}}$ and Kun Xiong ${ }^{1^{*}}$
}

\begin{abstract}
Background: Necroptosis is a type of regulated form of cell death that has been implicated in the pathogenesis of various diseases. Receptor-interacting protein 3 (RIP3), a member of the RIP family of proteins, has been reported as an important necroptotic pathway mediator in regulating a variety of human diseases, such as myocardial ischemia, inflammatory bowel disease, and ischemic brain injury. Our previous study showed that RIP3 was expressed in rat retinal ganglion cells (RGCs), where it was significantly upregulated during the early stage of acute high intraocular pressure. Furthermore, RIP3 expression was co-localized with propidium iodide (PI)-positive staining (necrotic cells). These results suggested that RIP3 up-regulation might be involved in the necrosis of injured RGCs. In this study, we aimed to reveal the possible involvement of RIP3 in oxygen glucose deprivation (OGD)-induced retinal ganglion cell-5 (RGC-5) necroptosis.
\end{abstract}

Methods: RGC-5 cells were cultured in Dulbecco's-modified essential medium and necroptosis was induced by $8 \mathrm{~h}$ OGD. PI staining and flow cytometry were performed to detect RGC-5 necrosis. RIP3 expression was detected by western blot and flow cytometry was used to detect the effect of RIP3 on RGC-5 necroptosis following OGD in rip3 knockdown cells. Malondialdehyde (MDA) lipid peroxidation assay was performed to determine the degree of oxidative stress.

Results: PI staining showed that necrosis was present in the early stage of OGD-induced RGC-5 cell death. The presence of RGC-5 necroptosis after OGD was detected by flow cytometry using necrostatin-1, a necroptosis inhibitor. Western blot demonstrated that RIP3 up-regulation may be involved in RGC-5 necroptosis. Flow cytometry revealed that the number of OGD-induced necrotic RGC-5 cells was reduced after rip3 knockdown. Furthermore, MDA levels in the normal RGC-5 cells were much higher than in the rip3-knockdown cells after OGD.

Conclusions: Our findings suggest that RGC-5 cell necroptosis following OGD is mediated by a RIP3-induced increase in oxidative stress.

Keywords: Retinal ganglion cell-5, Receptor-interacting protein 3, Oxygen glucose deprivation, Necroptosis, Oxidative stress

\section{Background}

Necrosis has been considered as an uncontrollable form of cell death for a long time, which has the morphological

\footnotetext{
*Correspondence: lixiangxue@hsc.pku.edu.cn; xiongkun2001@163.com

tWei Ding and Lei Shang contributed equally to the article

1 Department of Anatomy and Neurobiology, Morphological Sciences

Building, School of Basic Medical Sciences, Central South University, 172

Tongzi Po Road, Changsha 410013, Hunan, China

${ }^{2}$ Department of Biochemistry and Molecular Biology, Health Science

Center, Peking University, Beijing 100191, China

Full list of author information is available at the end of the article
}

features of losing plasma integrity and organelle swelling. Recently, more and more evidences have showed that necrosis can be regulated by TNF- $\alpha$, Fas ligand or ischemia-reperfusion, etc. The type of regulated form of necrosis termed necroptosis occurs in many cell types. Recent studies have shown the presence of necroptosis in glutamate-induced hippocampal neuronal injury $[1,2]$, oxygen glucose deprivation (OGD)-induced cortical neuronal damage [3, 4], and hemin-induced glial cell damage [5]. Rosenbaum et al. [6] found necroptotic 
cells in the retinal ganglion cell layer during acute high intra-ocular pressure (aHIOP). Several recent studies have suggested that receptor interacting protein 3 (RIP3) plays an important role in necroptosis in many cell types. Vieira et al. [7] showed that RIP3 mediated neuronal cell death and its expression was upregulated in primary hippocampal neurons following OGD-induced injury. Wang et al. [8] found that the expression of RIP3 could be suppressed by Necrostatin-1 (Nec-1) in ouabain-induced spiral ganglion neuronal injury. Viringipurampeer et al. [9] showed that morpholino gene knockdown of rip3 can rescue dying photoreceptors in a zebrafish model of retinal degeneration. Dvoriantchikova et al. [10] also showed that mouse RGC necroptosis might be caused by inflammatory responses induced by RIP3.

Though recent studies showed that mixed lineage kinase domain-like protein (MLKL) is downstream of RIP3 in necroptosis [11], the production of reactive oxygen species (ROS) mediated by the activation of RIPs is probably the most studied and well accepted mechanism. Zhang et al. examined TNF-induced necrosis in NIH 3T3 cells and showed that RIP3 regulates TNF-induced ROS overproduction by activating metabolic enzymes, leading to necrosis via damaging of cellular membranes and organelles [12]. Son et al. [13] showed that Nec-1 can significantly reduce ROS production in Theiler's murine encephalomyelitis virus (TMEV)-infected macrophages. Our previous studies showed that Timosaponin B-II, an anti-oxidative monomer extracted from Rhizoma anemarrhenae, reduced retinal ganglion cell-5 (RGC-5) cell necroptosis by inhibiting ROS accumulation [14]. Together, these results suggested that ROS accumulation might directly lead to necrosis.

In our previous study, we found that necroptosis occurs in RGC-5 at $24 \mathrm{~h}$ following elevated hydrostatic pressure (EHP) [15]. Moreover, our study showed that RIP3 was mainly expressed in RGCs in vivo in rats, and the expression of RIP3 is significantly upregulated at the early stage of aHIOP [16]. These results indicated that RIP3 might be involved in the necroptosis of RGCs following injury. Therefore, in our recent study we focused on the involvement of RIP3 during necroptosis. In the meantime, various pathophysiology mechanisms have been proposed to cause RGC damage during aHIOP in vivo, with high pressure being only one aspect [15]. Ischemia-hypoxia of RGCs induced by compression of the central retinal artery following aHIOP is a more important mechanism [17]. Therefore, the model of OGD-induced damage (the classical model in vitro to simulate ischemia-hypoxia) was applied in our present study to detect whether it could induce necroptosis in RGC-5 cells and to determine the role of RIP3 in this process. As mentioned above, ROS were indicated to play a direct role in
RIP3-mediated necroptosis, so this was also explored simultaneously. Our study will help gain a better understanding of the mechanism of RGC necrosis in acute hypoxic-ischemic retinal diseases and provide experimental evidence to determine a possible target for inhibiting this process in future translational medicine.

\section{Methods \\ Reagents}

Rabbit anti-RIP3 antibody, Nec-1, and propidium iodide (PI) were obtained from Sigma-Aldrich (St Louis, MO, USA), rabbit anti- $\beta$-tubulin was from Abcam (Cambridge, UK), and the fluorescein isothiocyanate-Annexin V/PI apoptosis assay kit was from Clontech (Mountain View, CA, USA). Morpholino oligonucleotides were synthesized by Gene Tools, LLC (Philomath, OR, USA). Bicinchoninic acid assay was purchased from Pierce (Rockford, IL, USA). Lipid peroxidation (MDA) was obtained from Jian-Cheng Biotechnical Co. (Nanjing, Jiangsu, China). Goat anti-rabbit secondary antibody was obtained from Jackson Immuno Research Inc. (Lancaster, PA, USA).

\section{Cell culture}

Mouse RGC- 5 cells were contributed by the Department of Ophthalmology, Second Hospital of Ji Lin University, China [18]. RGC-5 cells were grown in Dulbecco's modified Eagles medium (DMEM) (HyClone Laboratories, Inc., Logan, UT, USA) and supplemented with $10 \%$ fetal bovine serum (FBS, HyClone Laboratories, Inc.), $100 \mathrm{U} /$ $\mathrm{mL}$ penicillin and $100 \mu \mathrm{g} / \mathrm{mL}$ streptomycin (HyClone Laboratories, Inc.). The cells were grown at $37^{\circ} \mathrm{C}$ under a humidified atmosphere of $5 \% \mathrm{CO}_{2}$. The RGC-5 cells used in the experiment were with two to three passages postthawing to minimize variability in the assays based on our observations. The density of RGC- 5 cells was around $70 \%$ in $6 \mathrm{~mL}$ culture media in a 50-mL flask before OGD.

\section{OGD model and Nec- 1 use}

When the density of RGC-5 cells was around 70\%, cells were washed twice with glucose-free DMEM (SigmaAldrich), then placed in the same medium in an anaerobic chamber with $95 \% \mathrm{~N}_{2}$ and $5 \% \mathrm{CO}_{2}$ for $8 \mathrm{~h}$ at $37^{\circ} \mathrm{C}$ to induce OGD $[19,20]$. After $8 \mathrm{~h}, \mathrm{OGD}$ was terminated by removing the cell culture flasks from the anoxic chamber and replacing the glucose-free DMEM with regular culture medium. The cells were then maintained in a regular $5 \% \mathrm{CO}_{2}$ incubator to recover for each time point (6 and $12 \mathrm{~h})$.

Nec-1 was dissolved in dimethyl sulfoxide (DMSO) (AppliChem, Gatersleben, Germany) at $1 \mathrm{mg} / \mathrm{mL}$, and cells were pretreated with $10 \mu \mathrm{M}$ for $24 \mathrm{~h}$ before OGD. After $8 \mathrm{~h}$ in the hypoxic chamber, OGD was stopped by 
replacing the medium with regular culture medium containing Nec-1 [21].

\section{PI staining}

At each recovery time point ( 6 and $12 \mathrm{~h}$ ), the coverslips were washed in $0.01 \mathrm{M} \mathrm{PBS}$ for $3 \mathrm{~min}$, and incubated in $10 \mu \mathrm{g} / \mathrm{mL}$ PI-dye solution at $37^{\circ} \mathrm{C}$ for $30 \mathrm{~min}$. Subsequently, cells were washed in $0.01 \mathrm{M}$ PBS for $3 \mathrm{~min}$ and fixed in $4 \%$ paraformaldehyde for $20 \mathrm{~min}$. Then, cells were washed in PBS, counterstained with DAPI, and covered with anti-fading mounting medium before fluorescence microscopy (Nikon, Eclipse 80i, Tokyo, Japan). Motic pathology image analysis software (Motic Inc., Xiamen, China) was used to count cells.

\section{Western blot}

At each survival time point, cells were homogenized on ice in digestion buffer $[150 \mathrm{mM} \mathrm{NaCl}, 25 \mathrm{mM}$ Tris- $\mathrm{HCl}$ (pH 7.4), 2 mM EDTA, 1.0\% Triton X-100, 1.0\% sodium deoxycholate, $0.1 \%$ SDS] containing a cocktail of protease inhibitors (Sigma-Aldrich). Then, the homogenates were centrifuged at $10,000 \times g$ for $20 \mathrm{~min}$ at $4{ }^{\circ} \mathrm{C}$. The supernatants were collected and the protein concentration was determined using the bicinchoninic acid assay kit. A total of $100 \mu \mathrm{g}$ of protein in $62.5 \mathrm{mM}$ Tris loading buffer $(\mathrm{pH}$ 6.8 , containing $25 \%$ glycerol, $2 \%$ SDS, $0.01 \%$ bromophenol blue, and $5 \% \beta$-mercaptoethanol, Bio-Rad, Hercules, CA, USA) was boiled for 5 min, separated by SDS-polyacrylamide gel electrophoresis and transferred onto a nitrocellulose membrane (Bio-Rad). Non-specific binding was blocked with PBS containing 5\% nonfat milk (Bio$\mathrm{Rad}$ ) and 3\% bovine serum albumin (Sigma-Aldrich) for $1 \mathrm{~h}$. Membranes were incubated with anti-RIP3 (1:200) or anti- $\beta$-tubulin $(1: 1,000)$ antibodies overnight, washed, and subsequently incubated in HRP-conjugated secondary antibodies (1:20,000, Bio-Rad) for $2 \mathrm{~h}$. Immunoblotting products were visualized with an ECL Plus ${ }^{\mathrm{TM}}$ Western Blotting Detection kit according to the manufacturer's instruction (GE Healthcare Life Sciences, NJ, USA), and images were captured in a Molecular Dynamics Phosphorimager (Nucleo Tech Inc., CA, USA). Western blot bands were measured with Image $J$ (National Institutes of Health, MD, USA) to analyze the optical density (OD). The average OD of RIP3 and $\beta$-tubulin were compared, and the average relative value was obtained. Each experiment was repeated at least three times.

\section{Flow cytometry}

The cells attached to flasks were trypsinized, followed by a gentle wash. Cells were resuspended in $200 \mu \mathrm{L}$ of $1 \times$ binding buffer, following which $5 \mu \mathrm{L}$ of $20 \mu \mathrm{g} / \mathrm{mL}$ AnnexinV and $10 \mu \mathrm{L}$ of $50 \mathrm{mg} / \mathrm{mL}$ PI were added to the suspension, and incubated at room temperature for
15 min in the dark. Cells were then washed and analyzed by FACSCalibur ${ }^{\mathrm{TM}}$ (Becton, Dickinson Company, NJ, USA). The percentages of cells in each quadrant were analyzed using ModFit software (Verity Software House, ME, USA). Statistical analyses of flow cytometry results were conducted by calculating the number of PI-positive cells. All tests were repeated three times.

\section{Knockdown of rip3 expression using anti-sense morpholinos}

The expression of rip3 was inhibited using anti-sense morpholino oligos, following Garlapati's described method [22]. The rip3 morpholino oligo and standard control oligo were designed and purchased from Gene Tools LLC, whereby the rip3 morpholino oligo used for inhibition of rip 3 translation had the following sequence: $5^{\prime}$-AGGCCATAACTTGACA GAAGACATC- $3^{\prime}$. The standard control oligo sequence was as follows: 5'-CCTCTTACCTCAGTTACAATTTATA-3'. When the density of RGC- 5 cells was around $80 \%$, the cells were incubated with $1 \mu \mathrm{M}$ rip 3 morpholino oligo for $48 \mathrm{~h}$.

\section{Immunofluorescence staining}

Coverslips with fixed cells (rip3-knockdown and normal control) were washed in $0.01 \mathrm{M}$ PBS for $3 \mathrm{~min}$, incubated in 5\% BSA, followed by rabbit anti-RIP3 antibody (1:200) overnight. Then, cells were incubated with Cy3-conjugated donkey anti-rabbit secondary antibodies at 1:200 (Invitrogen, Carlsbad, CA, USA), and covered with an anti-fading mounting medium before microscopic examination (Eclipse 80i, Nikon, Tokyo, Japan).

\section{PCR analysis}

The cells cultured in the flasks were harvested and RNA was isolated using TRIzol reagent (Invitrogen). cDNA was synthesized using Thermoscript (Invitrogen) from $1 \mu \mathrm{g}$ of total RNA. Each primer pair $(\beta$-actin: forward primer 5'-CAACTTGATGTATGAA GGCTTTGGT-3', reverse primer 5'-ACTTTTATTGG TCTCAAGTCAGTGTACAG-3'; RIP3: forward primer, 5'-GATTTTGGCCTGTCCACGTT-3', reverse primer $5^{\prime}$-CAGGCCCAACTGATGTGTCC-3'). $\beta$-actin was used as the normalization control. The PCR conditions were as follows: $94^{\circ} \mathrm{C}$ for $3 \mathrm{~min}, 36$ cycles of $94^{\circ} \mathrm{C}$ for $45 \mathrm{~s}$, $55^{\circ} \mathrm{C}$ for $50 \mathrm{~s}$, and $72^{\circ} \mathrm{C}$ for $2 \mathrm{~min}$, with a final extension at $72^{\circ} \mathrm{C}$ for $10 \mathrm{~min}$.

\section{MDA concentration assay}

ROS levels were measured by MDA assay. At each survival time point, cells were digested by sonication on ice, in digestion buffer containing a cocktail of protease inhibitors. Then, the homogenates were centrifuged at $10,000 \times g$ for $20 \mathrm{~min}$ at $4{ }^{\circ} \mathrm{C}$. MDA levels in RGC-5 extracts were assayed using a commercial kit according 
to the manufacturer's instruction (Jian-Cheng Biotechnical Co.) as described in our previous study [23]. Equal quantities $(100 \mu \mathrm{g})$ of supernatant were loaded in each well and each analysis was performed in triplicate.

\section{Data analysis}

One-way analysis of variance was performed to test differences in average values between groups. All results were presented as mean \pm standard deviation. A value of $P<0.05$ was considered statistically significant. The data were analyzed by using SPSS 19.0 (SPSS Inc., Chicago, IL, USA).

\section{Results}

\section{Necroptosis induction following OGD}

PI staining was used to distinguish necrotic cells from normal ones [24, 25]. PI and DAPI double labeling showed that there was no obvious PI staining in the normal control group (CTL), while PI-positive cells were observed after 6 and $12 \mathrm{~h}$ of re-oxygenation following OGD (Fig. 1a). Meanwhile, the number of PI-positive cells after $6 \mathrm{~h}$ re-oxygenation was more than after $12 \mathrm{~h}$ $(P<0.05$, Fig. 1b).

The immunofluorescence results indicated that there was a large number of necrotic RGC-5 cells after $6 \mathrm{~h}$ reoxygenation following OGD; thus, we chose this time point to analyze cellular necroptosis by flow cytometry with PI/Annexin V double staining following pretreatment with Nec-1 (RGC-5 cells were incubated with $10 \mu \mathrm{M} \mathrm{Nec}-1$ for $24 \mathrm{~h}$ prior to OGD). The results showed that necrosis occurred after OGD (Fig. 2b), but the number of necrotic (PI-positive) cells decreased significantly with Nec-1 pretreatment (Fig. 2c, d, $P<0.05$ ). These results indicate that RGC-5 cell necrosis can be inhibited by Nec-1 and that necroptosis occurred at the early stage of OGD.

\section{RIP3 upregulation following OGD}

The western blot results showed that RIP3 mainly exhibited as a single $57-\mathrm{kDa}$ band in all groups (Fig. 3a). The bands in the 6- and 12-h re-oxygenation groups were thicker than the normal control group after OGD. Statistical analysis of OD values indicated that OGD up-regulated the expression of RIP3 at the early stage $(P<0.05$, Fig. $3 \mathrm{~b})$, with a significantly more intense RIP3 band evident in the 6-h re-oxygenation group.

\section{Preparation of rip3-knockdown RGC-5 cells}

RIP3 immunofluorescence revealed that when RGC-5 cells were treated with $1 \mu \mathrm{M}$ custom RIP3 antisense morpholino oligos for $48 \mathrm{~h}$, the intensity of fluorescence was weaker than the normal control (Fig. 4a, b). The western blot results showed that compared with normal RGC-5 cells and those treated with standard control oligos, the expression of RIP3 in rip3-knockdown cells was reduced (Fig. 4c). Statistical analysis of OD indicated that the difference was significant $(P<0.05$, Fig. 4 d). RT-PCR analysis showed a similar tendency at the mRNA level. $(P<0.05$, Fig. 4e, f). Together, these results indicate that rip3 knockdown in RGC-5 cells was successful.

\section{OGD-induced RGC-5 necroptosis mediated by RIP3}

Flow cytometry with PI/Annexin V double staining of rip3-knockdown and normal RGC-5 cells was applied to determine the involvement of RIP3 in OGD-induced necroptosis after $6 \mathrm{~h}$ re-oxygenation. The results showed

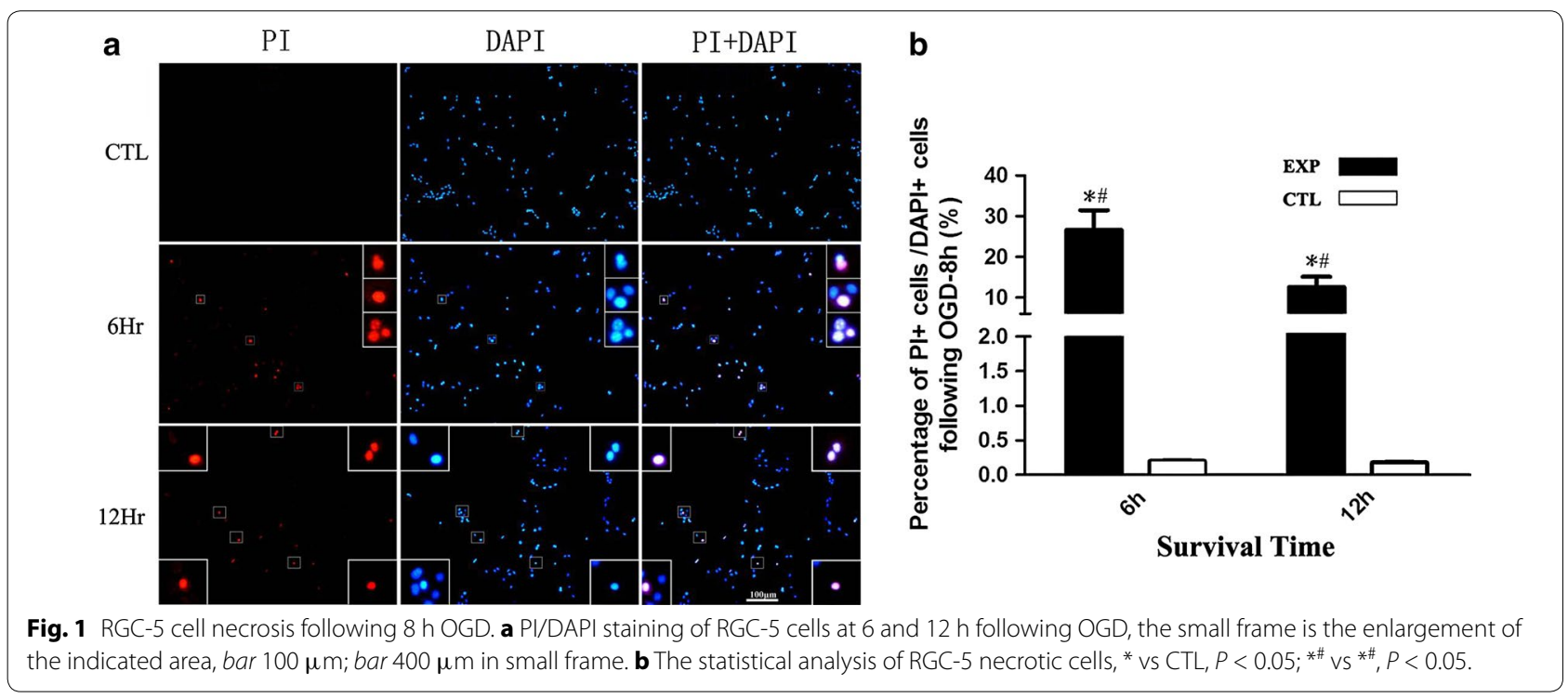



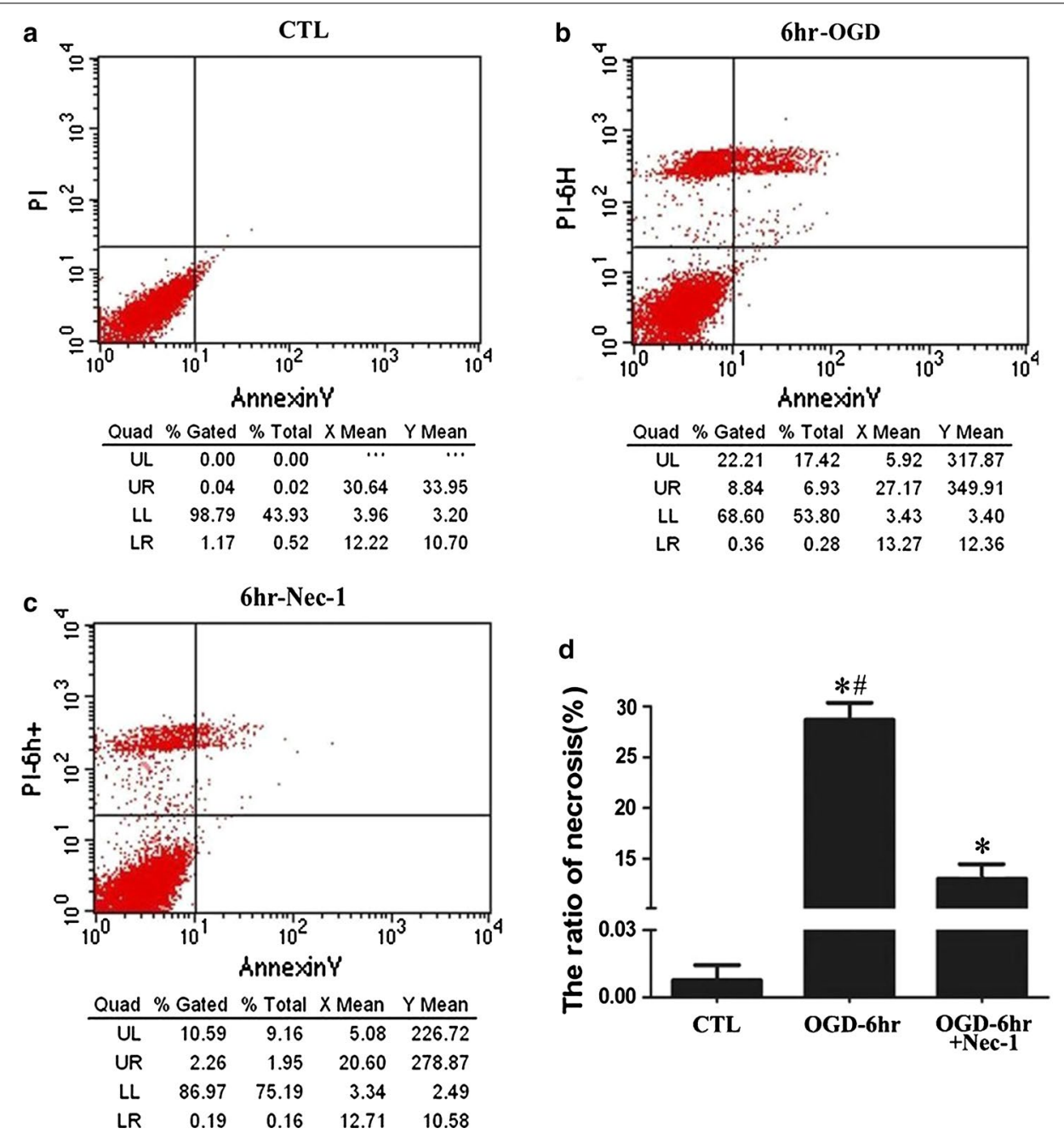

Fig. 2 Ratio of necrotic cells is reduced following Nec-1 pre-treatment by OGD. a Normal control cells; b RGC-5 cell necrosis after OGD; c RGC-5 cells were pre-treated with Nec-1 (10 $\mu \mathrm{M})$ to block necroptosis for $24 \mathrm{~h}$ before OGD and analysis of necroptotic cells. Cells were stained with Annexin fluorescein isothiocyanate and PI, and analyzed by FACS using FL1 (Annexin V) and FL3 (PI) channels. d The statistical analysis of RGC-5

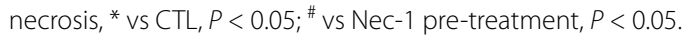

that there were more necrotic cells in both the normal OGD group and rip3-knockdown OGD group compared with the normal control group (Fig. 5a-c). However, the number of PI-positive cells in the rip3-knockdown group was decreased significantly compared with the normal OGD group $(P<0.05$, Fig. $5 \mathrm{~d})$.

\section{MDA levels in rip3-knockdown RGC-5 cells decreased following $O G D$}

The MDA concentration assay showed that after $6 \mathrm{~h}$ reoxygenation, MDA levels in the normal OGD group and the rip3-knockdown OGD group increased significantly compared with the normal control group, but the level of MDA in the rip3-knockdown OGD group decreased significantly compared with the normal OGD group $(P<0.05$, Fig. 6$)$.

\section{Discussion}

As a form of regulated cell death, necroptosis has attracted widespread attention in recent years. A growing number of studies have confirmed the presence of necroptosis in many diseases. Necroptosis has been indicated in injured cells in tumor necrosis factor (TNF)-induced murine fibrosarcoma L929 cells [26], TNF-induced tubular epithelial cells of donor kidneys [27], pathogenic free-living Naegleria fowleri-induced Jurkat T cells [28], TNF-related apoptosis-inducing ligand (TRAIL)-induced HepG2 cells [29], and acetaminopheninduced acute liver failure, to name a few [30]. Necroptosis was first found in non-neuronal cells; however, recent studies indicated it could also occur in neurons. Studies showed that in rat spinal cord injury, Nec-1 could protect 

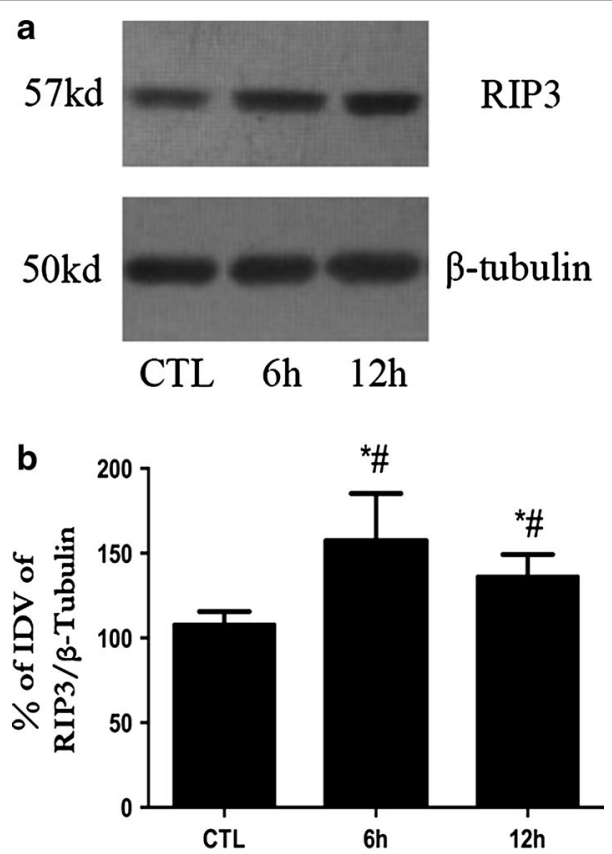

Fig. 3 RIP3 protein expression is up-regulated after OGD. a Western blot bands of RIP3 and $\beta$-tubulin expression; $\mathbf{b}$ OD analysis of RIP3; error bars represent standard deviation, ${ }^{*} \mathrm{vs} C T \mathrm{~L}, P<0.05$; ${ }^{*} \mathrm{vs}$, $P<0.05$.

neurons and improve physiological function at the early stage [31]. Dai et al. [32] revealed that necroptosis occurred in primary cortical neurons, which were injured by ferrous chloride. Li et al. [33] reported that $2 \mathrm{~h}$ after exposure to $N$-methyl-D-aspartic acid (NMDA), necroptosis occurred in cultured cortical neurons. Rosenbaum et al. [6] found a number of necroptotic cells in the rat retinal ganglion cell layer at $6 \mathrm{~h}$ after aHIOP. Our previous studies also indicated that necroptosis occurred in RGC-5 cells at an early stage following elevated hydrostatic pressure in vitro [15] or $300 \mu \mathrm{M}$ hydrogen peroxide $\left(\mathrm{H}_{2} \mathrm{O}_{2}\right)$ treatment [14]. Recently, in vitro models of OGD have been widely applied to simulate neuronal ischemia in vivo. Wang et al. [34] reported that the OGD model (6 h OGD followed by $24 \mathrm{~h}$ re-oxygenation) in cultured cortical neurons mimicked cerebral ischemia, and Tasca et al. [35] induced OGD in primary neurons to mimic the cellular death observed in models of brain ischemia in vivo. Therefore, we chose the OGD model in this study and the data indicated that necrosis occurred following $8 \mathrm{~h}$ OGD, with the number of necrotic cells increasing obviously after 6 and $12 \mathrm{~h}$ re-oxygenation. Flow cytometry also detected more necrotic cells at $6 \mathrm{~h}$ after re-oxygenation. More importantly, the number of necrotic cells significantly reduced following pretreatment with Nec-1. Together, these results suggest that necroptosis might be a form of cell death that widely exists in injured cells.
Many scientists have investigated the regulatory mechanism of necroptosis. Many different molecules were considered to participate in the occurrence and regulation of necroptosis, such as $\mathrm{HtrA} / \mathrm{Omi}$, ubiquitin C-terminal hydrolase (UCH-L1) [36], CDGSH ironsulfur domain-containing protein 1 (CISD1) [37], and calpain [38]. Of the numerous pathways investigated for their involvement in necroptosis, the RIP signaling pathway was the one that was first studied and gained the most attention. For instance, previous studies indicated that the expression of RIP1 was upregulated in OGDinduced neuronal damage and mediated necroptosis [3]. Roychowdhury et al. [39] revealed that RIP3-driven necroptosis was a key step of ethanol-induced hepatocyte injury. A recent study showed that RIP3 interacted with RIP1 via the RIP homotypic interaction motif (RHIM), when apoptosis was interrupted and, therefore, induced necroptosis by direct or indirect phosphorylation [40]. Phosphorylation of RIP3 promoted the phosphorylation of RIP1, which activated key enzymes of metabolic pathways and increased ROS production, thereby inducing necroptosis [41]. More recently, a study showed that following mutation of rip3, carbobenzoxy-valyl-alanylaspartyl-[O-methyl]-fluoromethylketone (zVAD) inhibited TNF- $\alpha$ induced apoptosis, but did not promote necroptosis, Therefore, RIP3 was the key target regulating necroptosis [12]. Our previous study indicated that the expression of RIP3 was upregulated at the early stage of aHIOP [16]. Thus, in this study, we focused on confirming the involvement of RIP3 in OGD-induced RGC-5 necroptosis. The western blot results showed that after $8 \mathrm{~h}$ OGD and 6 or $12 \mathrm{~h}$ re-oxygenation, RIP3 expression was significantly upregulated, suggesting that the RIP3 upregulation may be related to OGD-induced necroptosis. When rip3 was knocked down using morpholino oligos, flow cytometry results showed that the number of necrotic cells was significantly reduced compared with the normal OGD group. Again, these results suggest that RIP3 is a key molecule mediating OGD-induced RGC-5 cell necroptosis. Furthermore, we observed that the MDA concentration, which describes the degree of oxidant stress, increased significantly after OGD compared with the normal control. Furthermore, MDA concentration decreased significantly in rip3-knockdown cells compared with normal controls following OGD. According to the data described herein, we speculated that OGDinduced RGC-5 necroptosis might be caused by RIP3 upregulation-mediated ROS accumulation resulting in necrosis. Shindo et al. [42] also reported similar results, whereby RIP-mediated necroptosis was associated with ROS accumulation in mouse embryo fibroblasts (MEFs).

Though RIP3 was shown to regulate OGD-induced RGC-5 necroptosis, the flow cytometry results showed 


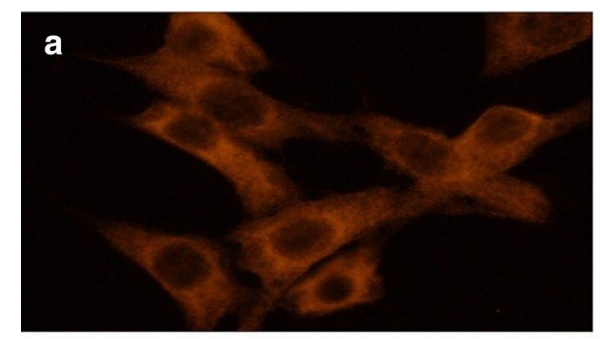

C

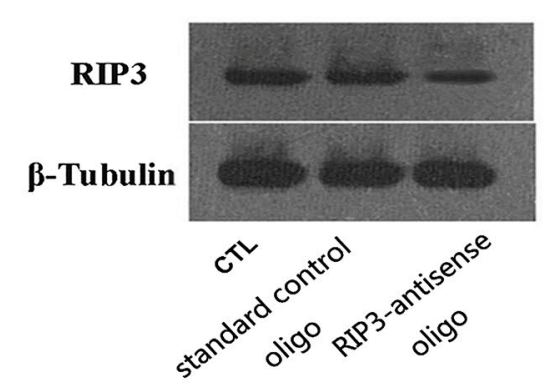

e

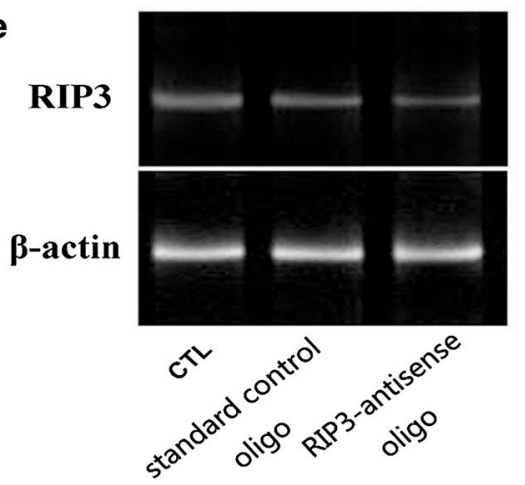

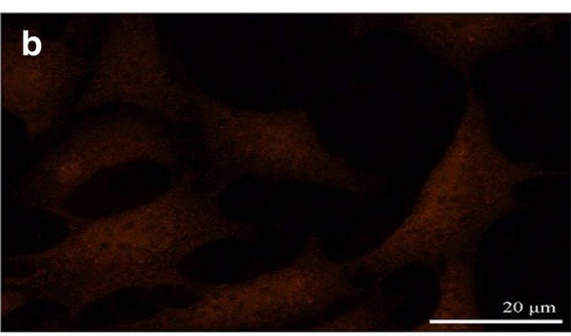
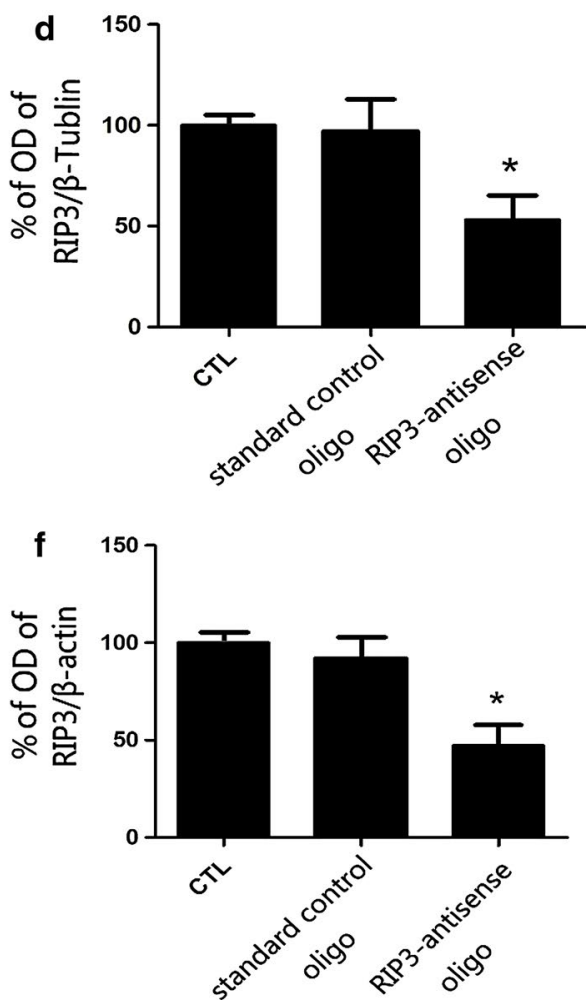

Fig. 4 Establishment of RGC-5 rip3 knockdown cell line. RIP3 immunofluorescence staining of RGC-5 cells after rip3 knockdown (a normal RGC-5; b rip3-knockdown RGC-5). Western blot results (c, d). PCR results (e, f), bar $20 \mu \mathrm{m}$ in $\mathbf{a}, \mathbf{b}$, * ${ }^{*} \mathrm{Vs} C T L, P<0.05$.

that it was not completely inhibited when the expression of RIP3 was inhibited. Furthermore, the level of MDA was higher in rip3-knockdown RGC-5 OGD group compared with normal control group. We speculated that there are three reasons that may account for this phenomenon. First, there might exist other necroptosisindependent forms of cell death responsible for RGC-5 cell necrosis. Second, although RIP3 was inhibited by morpholino oligo, the expression of RIP3 was not completely inhibited, therefore the remaining RIP3 could still partially maintain function. Third, many other molecules, such as calpain, HtrA2/Omi, UCH-L1, and CISD1, could be involved in the regulation of necroptosis, whereby the RIP3 signaling pathway would not be the unique regulatory mechanism.
It should be noted that our results show that changes in the ratio in upper left quadrants in the Nec-1 pretreatment group were less than rip3 knockdown group following OGD, whereas changes in upper right quadrants in the Nec-1 pretreatment group were more than the rip3 knockdown group following OGD. Based on Ormerod's analysis of flow cytometry results [43], the upper left (UL) quadrant contains dead cells or cell fragments, the upper right (UR) quadrant contains necrotic or late apoptotic cells. Moreover, in vivo aHIOP $[44,45]$ or in vitro OGD [46] analyses revealed that the majority of RGC deaths were necrotic like at the early stage $(3,4$, or $12 \mathrm{~h}$ ) of retinal ischemia, whereas apoptosis occurs at $24 \mathrm{~h}$ or later after ischemia. Therefore, we speculated that the protective effect of Nec-1 pretreatment was not as effective as 
a

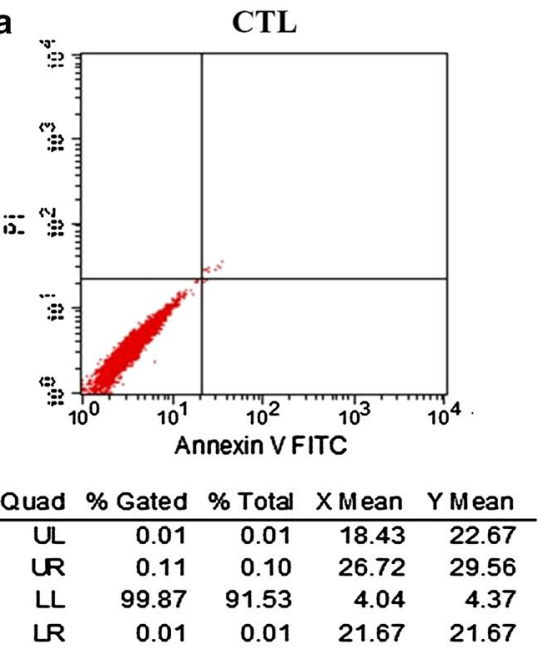

C
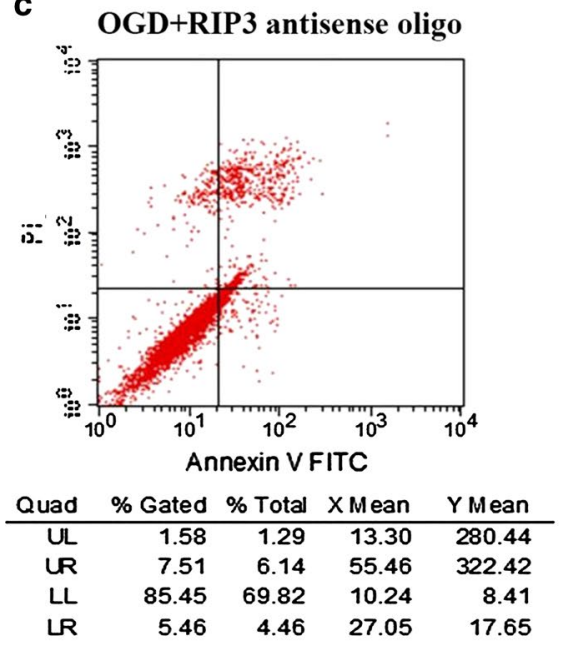

b

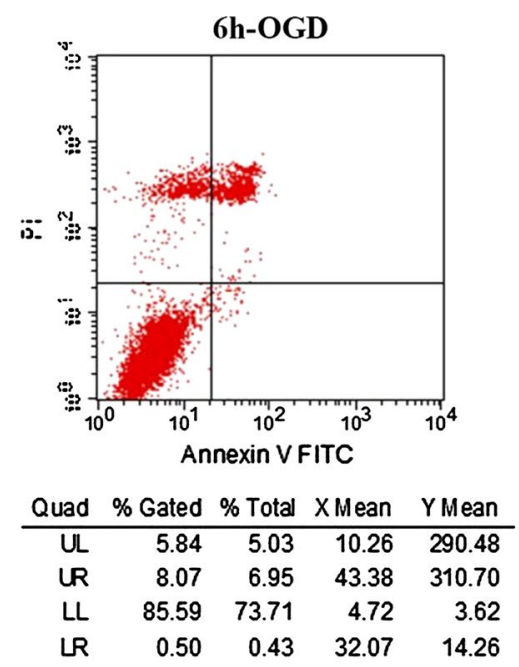

d

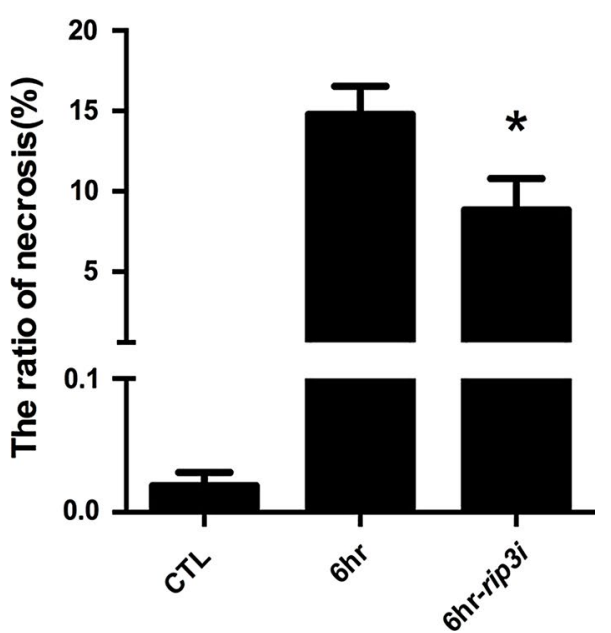

Fig. 5 The ratio of necrotic cells decreased following rip3 knockdown by OGD. a Normal RGC-5; b normal RGC-5 necrosis after OGD; c rip3-knockdown RGC-5 necrosis after OGD. d The statistical analysis of RGC-5 necrosis, * vs OGD, $P<0.05$.

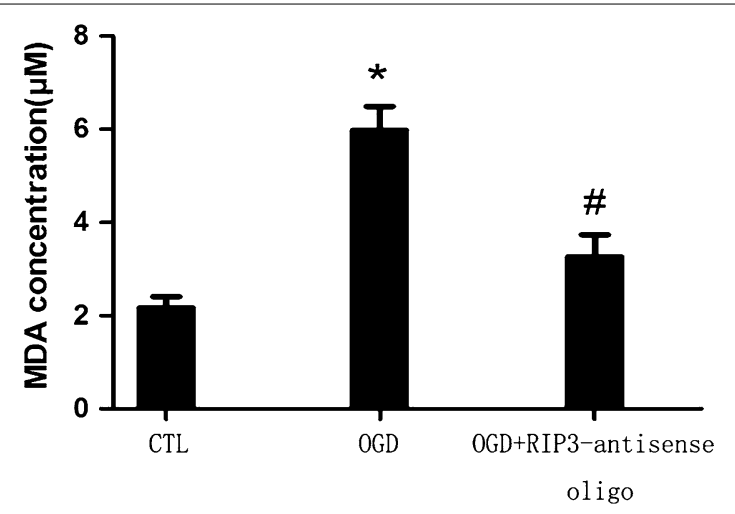

Fig. 6 MDA is reduced following rip3 knockdown by OGD insult. * vs ${ }^{\#} P<0.05 ;$; VS $C T L, P<0.05$ rip3 knockdown in strongly necrotic cells after OGD and $6 \mathrm{~h}$ re-oxygenation. However, further research is required to confirm these findings.

In conclusion, our results indicate that RIP3 induces RGC-5 cell necroptosis following OGD via ROS accumulation. Our research may help find a suitable biological target, such as RIP3 or ROS, to prevent RGC necroptosis.

\section{Authors' contributions}

$K X$ and $L X X$ designed the experiment, WD and LS performed the experiment, $\mathrm{NL}$ and DC analyzed the data, WD and LS drafted the manuscript, KX and JFH participated in paper modification, LXX revised the manuscript for English writing, and all authors participated in critical revision of the manuscript. All authors read and approved the final manuscript. 


\section{Author details}

${ }^{1}$ Department of Anatomy and Neurobiology, Morphological Sciences Building, School of Basic Medical Sciences, Central South University, 172 Tongzi Po Road, Changsha 410013, Hunan, China. ${ }^{2}$ Department of Biochemistry and Molecular Biology, Health Science Center, Peking University, Beijing 100191, China.

\section{Acknowledgements}

This study was supported by the National Natural Science Foundation of China (81371011); National Key Technologies Research and Development Program of China (2012BAK14B03); Wu Jie-Ping Medical Foundation of the Minister of Health of China (320.6750.14118); Natural Science Foundation of Hunan Province (2015JJ2187); and the Teacher Research Foundation of Central South University (2014JSJJ026)

\section{Compliance with ethical guidelines}

\section{Competing interests}

The authors declare that they have no competing interests.

Received: 13 April 2015 Accepted: 15 July 2015

Published online: 04 August 2015

\section{References}

1. Zhang M, Li J, Geng R, Ge W, Zhou Y, Zhang C et al (2013) The inhibition of ERK activation mediates the protection of necrostatin-1 on glutamate toxicity in HT-22 cells. Neurotox Res 24(1):64-70

2. Xu X, Chua CC, Kong J, Kostrzewa RM, Kumaraguru U, Hamdy RC et al (2007) Necrostatin-1 protects against glutamate-induced glutathione depletion and caspase-independent cell death in HT-22 cells. J Neurochem 103(5):2004-2014

3. Chen WW, Yu H, Fan HB, Zhang CC, Zhang M, Zhang C et al (2012) RIP1 mediates the protection of geldanamycin on neuronal injury induced by oxygen-glucose deprivation combined with zVAD in primary cortical neurons. J Neurochem 120(1):70-77

4. Meloni BP, Meade AJ, Kitikomolsuk D, Knuckey NW (2011) Characterisation of neuronal cell death in acute and delayed in vitro ischemia (oxygen-glucose deprivation) models. J Neurosci Methods 195(1):67-74

5. Laird MD, Wakade C, Alleyne CJ, Dhandapani KM (2008) Hemin-induced necroptosis involves glutathione depletion in mouse astrocytes. Free Radic Biol Med 45(8):1103-1114

6. Rosenbaum DM, Degterev A, David J, Rosenbaum PS, Roth S, Grotta JC et al (2010) Necroptosis, a novel form of caspase-independent cell death, contributes to neuronal damage in a retinal ischemia-reperfusion injury model. J Neurosci Res 88(7):1569-1576

7. Vieira M, Fernandes J, Carreto L, Anuncibay-Soto B, Santos M, Han J et al (2014) Ischemic insults induce necroptotic cell death in hippocampal neurons through the up-regulation of endogenous RIP3. Neurobiol Dis 68:26-36

8. Wang X, Wang Y, Ding ZJ, Yue B, Zhang PZ, Chen XD et al (2014) The role of RIP3 mediated necroptosis in ouabain-induced spiral ganglion neurons injuries. Neurosci Lett 578:111-116

9. Viringipurampeer IA, Shan X, Gregory-Evans K, Zhang JP, Mohammadi Z, Gregory-Evans CY (2014) Rip3 knockdown rescues photoreceptor cell death in blind pde6c zebrafish. Cell Death Differ 21(5):665-675

10. Dvoriantchikova G, Degterev A, Ivanov D (2014) Retinal ganglion cell (RGC) programmed necrosis contributes to ischemia-reperfusioninduced retinal damage. Exp Eye Res 123:1-7

11. Cai Z, Jitkaew S, Zhao J, Chiang HC, Choksi S, Liu J et al (2014) Plasma membrane translocation of trimerized MLKL protein is required for TNFinduced necroptosis. Nat Cell Biol 16(1):55-65

12. Zhang DW, Shao J, Lin J, Zhang N, Lu BJ, Lin SC et al (2009) RIP3, an energy metabolism regulator that switches TNF-induced cell death from apoptosis to necrosis. Science 325(5938):332-336

13. Son KN, Lipton HL (2015) Inhibition of Theiler's virus-induced apoptosis in infected murine macrophages results in necroptosis. Virus Res 195:177-182
14. Jiang SH, Shang L, Xue LX, Ding W, Chen S, Ma RF et al (2014) The effect and underlying mechanism of Timosaponin B-II on RGC-5 necroptosis induced by hydrogen peroxide. BMC Complement Altern Med 14:459

15. Shang L, Huang JF, Ding W, Chen S, Xue LX, Ma RF et al (2014) Calpain: a molecule to induce AIF-mediated necroptosis in RGC-5 following elevated hydrostatic pressure. BMC Neurosci 15:63

16. Huang JF, Shang L, Zhang MQ, Wang H, Chen D, Tong JB et al (2013) Differential neuronal expression of receptor interacting protein 3 in rat retina: involvement in ischemic stress response. BMC Neurosci 14:16

17. Sappington RM, Chan M, Calkins DJ (2006) Interleukin-6 protects retinal ganglion cells from pressure-induced death. Invest Ophthalmol Vis Sci 47(7):2932-2942

18. Li GY, Li T, Fan B, Zheng YC, Ma TH (2012) The D(1) dopamine receptor agonist, SKF83959, attenuates hydrogen peroxide-induced injury in RGC-5 cells involving the extracellular signal-regulated kinase/p38 pathways. Mol Vis 18:2882-2895

19. Liu RL, Xiong QJ, Shu Q, Wu WN, Cheng J, Fu H et al (2012) Hyperoside protects cortical neurons from oxygen-glucose deprivation-reperfusion induced injury via nitric oxide signal pathway. Brain Res 1469:164-173

20. Du S, Mao G, Zhu T, Luan Z, Du Y, Gu H (2015) TIMP1 in conditioned media of human adipose stromal cells protects neurons against oxygenglucose deprivation injury. Neurosci Lett 584:56-59

21. Xu X, Chua KW, Chua CC, Liu CF, Hamdy RC, Chua BH (2010) Synergistic protective effects of humanin and necrostatin-1 on hypoxia and ischemia/reperfusion injury. Brain Res 1355:189-194

22. Garlapati S, Saraiya AA, Wang CC (2011) A La autoantigen homologue is required for the internal ribosome entry site mediated translation of giardiavirus. PLoS One 6(3):e18263

23. Huang JF, Shang L, Liu P, Zhang MQ, Chen S, Chen D et al (2012) Timosaponin-BIl inhibits the up-regulation of BACE1 induced by ferric chloride in rat retina. BMC Complement Altern Med 12:189

24. Krysko DV, Vanden BT, D'Herde K, Vandenabeele P (2008) Apoptosis and necrosis: detection, discrimination and phagocytosis. Methods 44(3):205-221

25. Fu Z, Deng B, Liao Y, Shan L, Yin F, Wang Z et al (2013) The anti-tumor effect of shikonin on osteosarcoma by inducing RIP1 and RIP3 dependent necroptosis. BMC Cancer 13:580

26. Zhong CQ, Li Y, Yang D, Zhang N, Xu X, Wu Y et al (2014) Quantitative phosphoproteomic analysis of RIP3-dependent protein phosphorylation in the course of TNF-induced necroptosis. Proteomics 14(6):713-724

27. Lau A, Wang S, Jiang J, Haig A, Pavlosky A, Linkermann A et al (2013) RIPK3-mediated necroptosis promotes donor kidney inflammatory injury and reduces allograft survival. Am J Transplant 13(11):2805-2818

28. Song KJ, Jang YS, Lee YA, Kim KA, Lee SK, Shin MH (2011) Reactive oxygen species-dependent necroptosis in Jurkat T cells induced by pathogenic free-living Naegleria fowleri. Parasite Immunol 33(7):390-400

29. Jouan-Lanhouet S, Arshad MI, Piquet-Pellorce C, Martin-Chouly C, Le Moigne-Muller G, Van Herreweghe F et al (2012) TRAIL induces necroptosis involving RIPK1/RIPK3-dependent PARP-1 activation. Cell Death Differ 19(12):2003-2014

30. Zhang YF, He W, Zhang C, Liu XJ, Lu Y, Wang H et al (2014) Role of receptor interacting protein (RIP) 1 on apoptosis-inducing factor-mediated necroptosis during acetaminophen-evoked acute liver failure in mice. Toxicol Lett 225(3):445-453

31. Wang $Y$, Wang $H$, Tao $Y$, Zhang S, Wang J, Feng $X$ (2014) Necroptosis inhibitor necrostatin-1 promotes cell protection and physiological function in traumatic spinal cord injury. Neuroscience 266:91-101

32. Dai MC, Zhong ZH, Sun YH, Sun QF, Wang YT, Yang GY et al (2013) Curcumin protects against iron induced neurotoxicity in primary cortical neurons by attenuating necroptosis. Neurosci Lett 536:41-46

33. Li Y, Yang X, Ma C, Qiao J, Zhang C (2008) Necroptosis contributes to the NMDA-induced excitotoxicity in rat's cultured cortical neurons. Neurosci Lett 447(2-3):120-123

34. Wang CP, Li GC, Shi YW, Zhang XC, Li JL, Wang ZW et al (2014) Neuroprotective effect of schizandrin A on oxygen and glucose deprivation/ reperfusion-induced cell injury in primary culture of rat cortical neurons. J Physiol Biochem 70(3):735-747

35. Tasca Cl, Dal-Cim T, Cimarosti H (2015) In vitro oxygen-glucose deprivation to study ischemic cell death. Methods Mol Biol 1254:197-210 
36. Sosna J, Voigt S, Mathieu S, Kabelitz D, Trad A, Janssen O et al (2013) The proteases HtrA2/Omi and UCH-L1 regulate TNF-induced necroptosis. Cell Commun Signal 11:76

37. Shulga N, Pastorino JG (2014) Mitoneet mediates TNFalpha-induced necroptosis promoted by exposure to fructose and ethanol. J Cell Sci 127(Pt 4):896-907

38. Cabon L, Galan-Malo P, Bouharrour A, Delavallee L, Brunelle-Navas MN, Lorenzo HK et al (2012) BID regulates AIF-mediated caspase-independent necroptosis by promoting BAX activation. Cell Death Differ 19(2):245-256

39. Roychowdhury S, McMullen MR, Pisano SG, Liu X, Nagy LE (2013) Absence of receptor interacting protein kinase 3 prevents ethanolinduced liver injury. Hepatology 57(5):1773-1783

40. Cho YS, Challa S, Moquin D, Genga R, Ray TD, Guildford M et al (2009) Phosphorylation-driven assembly of the RIP1-RIP3 complex regulates programmed necrosis and virus-induced inflammation. Cell 137(6):1112-1123

41. Vandenabeele P, Galluzzi L, Vanden BT, Kroemer G (2010) Molecular mechanisms of necroptosis: an ordered cellular explosion. Nat Rev Mol Cell Biol 11(10):700-714
42. Shindo R, Kakehashi H, Okumura K, Kumagai Y, Nakano H (2013) Critical contribution of oxidative stress to TNFalpha-induced necroptosis downstream of RIPK1 activation. Biochem Biophys Res Commun 436(2):212-216

43. Ormerod MG (2000) Flow cytometry: a practical approach, 3rd edn. Oxford University Press, Oxford

44. Joo CK, Choi JS, Ko HW, Park KY, Sohn S, Chun MH et al (1999) Necrosis and apoptosis after retinal ischemia: involvement of NMDA-mediated excitotoxicity and p53. Invest Ophthalmol Vis Sci 40(3):713-720

45. Buchi ER (1992) Cell death in the rat retina after a pressure-induced ischaemia-reperfusion insult: an electron microscopic study. I. Ganglion cell layer and inner nuclear layer. Exp Eye Res 55(4):605-613

46. Dvoriantchikova G, Barakat DJ, Hernandez E, Shestopalov VI, Ivanov D (2010) Liposome-delivered ATP effectively protects the retina against ischemia-reperfusion injury. Mol Vis 16:2882-2890

\section{Submit your next manuscript to BioMed Central and take full advantage of:}

- Convenient online submission

- Thorough peer review

- No space constraints or color figure charges

- Immediate publication on acceptance

- Inclusion in PubMed, CAS, Scopus and Google Scholar

- Research which is freely available for redistribution

Submit your manuscript at 